\begin{tabular}{|c|c|}
\hline \multirow{3}{*}{ 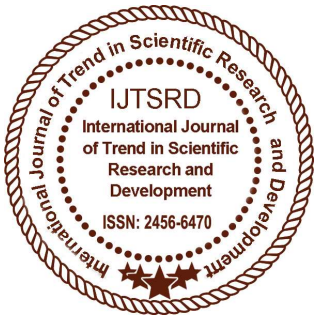 } & $\begin{array}{l}\text { International Journal of Trend in Scientific } \\
\text { Research and Development (IJTSRD) }\end{array}$ \\
\hline & International Open Access Journal \\
\hline & ISSN No: 2456 - 6470 | www.ijtsrd.com | Volume - 1 | Issue - 6 \\
\hline
\end{tabular}

\title{
An Enhanced Agglomerative Clustering Algorithm for Solving Vehicle Routing Problem
}

\author{
V. Praveen \\ Assistant Professor, CSE, \\ N.S.N College of Engineering \& \\ Technology, Karur, Tamilnadu
}

\author{
V. Hemalatha \\ Assistant Professor, CSE, \\ N.S.N College of Engineering \& \\ Technology, Karur, Tamilnadu
}

\author{
M. Poovizhi \\ Assistant Professor, CSE, \\ N.S.N College of Engineering \& \\ Technology, Karur, Tamilnadu
}

\begin{abstract}
An aggrandized solution is designed for the vehicles to reduce the total cost of distribution by which it can supply the goods to the customers with its known capacity can be named as a vehicle routing problem. In variable Neighborhood search method, mainly an efficient vehicle routing can be achieved by calculating the distance matrix value based on the customer's location or the path where the customer's resides. The main objective of the paper is to reduce the total distance travelled to deliver the goods to the customers. The proposed algorithm is a hierarchy based enhanced agglomerative clustering algorithm technique which is used in the data mining scenario effectively. The proposed algorithm decreases the total distance assigning to each route and the important thing need to consider is that, this enhanced clustering algorithm can reduce the total distance when compared to the previously proposed variable Neighborhood search method.
\end{abstract}

Keywords: High Performance Concrete, Marble Dust, Steel fibers, Super Plasticizer.

\section{Introduction}

In general, there are many practical applications which can provide efficient distribution of goods to the customers. Goods in the sense it can be any home appliance products which are used daily. The vehicle scheduling problem was first formulated in the year 1959 [3] and in that set of customers with each of its known locations and known demand for any commodity, and that required goods can be delivered to the customer from a single depot by some calculated amount of delivery vehicles with some basic conditions and constraints are specified [1]:

(i) The demands of all customers are met

(ii) Each customer is served by exactly one vehicle

(iii) For each route the total demands must not exceed the capacity of the vehicle which is already defined.

From a depot different products must be distributed to several retailers. An efficient collection (or) distribution of goods keeps transport inventories low, it saves resources and energy. Therefore, vehicle routing is one of the important topics for this kind of problems.

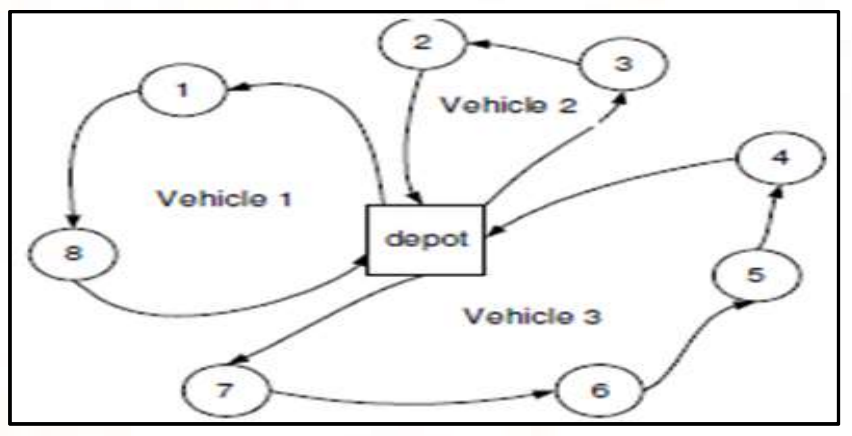

Fig.1 Example for Vehicle Routing Problem

The vehicle routing problem is a common name given to a whole class of problems involving the visiting of customers by using vehicles. These problems derive 
their name from the basic practical problem of supplying geographically dispersed customers with goods using a number of vehicles operating from a common goods depot (or) warehouse.

An example for a single repository based vehicle routing problem is shown in the Figure 1. For a classical vehicle routing problem, the best solution is to serve the goods to the customers exactly once by starting from and ending to the depot.

The main objective is to reduce the overall transportation cost by satisfying all the constraints. The cost for transporting the goods can be reduced by minimizing the total distance travelled and as well as the total number of vehicles. While comparable to the classical vehicle routing problem, the majority of the real world problems are much more complex to solve. In general, the classical vehicle routing problem is based on some constraints like the total vehicle capacity or some time interval to reach the customers.

A single depot vehicle routing problem uses a single depot (or) warehouse for delivering the goods to the customers, several algorithms and saving methods are proposed for solving the single depot based real time problems. In general, the VRP is a Combinatorial Optimization Problem and it consists of two main things are depot and destinations. A formal example for this kind of problem is Soft Drink Company. In that they are travelling from the company to all the retail stores to distribute the products and again came back to the company. The main constraint followed is to visit the customers only once.

Vehicle routing problem is also known as delivery problem. For example, sewage must be collected from households and industries to a distracting place, so for that transportation everyone needs an efficient route to travel from one place to another. It is very much useful for the day to day transportation because it reduces the cost of forming the routes based on the capacity of the vehicle.

The rest of the paper is organized as follows. Section II presents the literature review. Section III presents a statistical example, using variable Neighborhood search method. Section IV describes the proposed methodology based on Agglomerative clustering algorithm method. Section V describes the comparison results. The final conclusion is presented in Section VI.

\section{Literature Survey}

The first article for the 'Truck dispatching problem' was published by Dantzig and Ramser presented a larger truck dispatching problem, that is referred to as D\&R problem and many more enhanced solutions are found which is similar to this article after it was published.

The Clark and Wright algorithm[4] is one of the most popular heuristic algorithms in the vehicle routing problem area. Cordeau et al. described an analysis that parallel version is much better because merge yielding the largest saving is always implemented, but the sequential version keeps expanding the same route until there is no longer feasible route.

Chopra and Meindl [2] provide a solution for vehicle route planning, in that they present a routing and scheduling, transportation problem for a company in which they use a method called savings matrix method. The algorithm can be classified into four steps which are: (1) Identify the distance matrix for the given location, (2) calculating the saving matrix using the distance matrix values, (3) assigns, customers to vehicles or routes, and (4) sequence the customers within the routes. The first two steps are explained clearly. The third step is that assign the customers to vehicles and routes by, initially each customer are assigned to a separate route. If the two routes can provide a feasible solution by which it doesn't cross the limited capacity means it can be combined. The procedure is continued until no more feasible combinations are possible.

For a transportation problem, Lumsden and Jonsson described a similar explanation but it is not clear. Rand[6] made an analysis and presents an article about the different saving methods for the vehicle routing problems. In that he argues about the parallel version, because it is not always better than the sequential version. Parallel version is a heuristic and there is no guarantee from the obtained results that it produces the optimal solution or near optimal solution.

The Tabu Search heuristic algorithm [7] for the vehicle routing problem having both capacity and route length restrictions. The algorithm considers a sequence of adjacent solutions obtained by repeatedly removing a vertex from its current route and reinserting it into another route. This is done by means of a generalized insertion procedure previously developed by the authors. During the course of the 
algorithm, infeasible solutions are allowed. Numerical tests on a set of benchmark problems indicate that Tabu Search outperforms the best existing heuristics, and Tabu route often produces the best known solutions. So many new methods can produce best results compared to Tabu Search.

The Adaptive Memory Procedure (AMP) [8] was first proposed by Rochat and Taillard. It is an enhancement of Tabu Search (TS) to solve the VRP. It was motivated by the work of Glover regarding surrogate constraints. An important principle behind AMP is that good solutions may be constructed by combining different components of other good solutions. A memory con- 5 training components of visited solutions is kept. Periodically, a new solution is constructed using the data in the memory and improved by a local search procedure.

For the VRP problem, a Variable Neighborhood Search algorithm[9] in which four Neighborhood structures are designed to find the planning of trips within the four different Neighborhood structures. By which two of them is used to minimize the total length and the other two is used to minimize the overall time. It includes a shaking step where three of the Neighborhood structures are probably used based on the need. The algorithm was tested over a set of benchmark problems and the obtained solutions were compared with five previously proposed algorithms.

\section{Statistical Example}

The ultimate base for the vehicle routing problem is travelling salesman problem because the impulsion is "visit all the customers only once" used in the vehicle routing problem is as same as that of travelling salesman problem. Depict that a delivery man must visit some ' $n$ ' number of customers and returned to the starting point after visiting all the customers only once and the total cost for visiting all the customers is the dominant problem.

The solution is to obtain a minimum [5] cost line to visit all the customers only once. Infer when the cost for travel from city a to city $b$ is equals to the cost of city $b$ to city a, then the problem is considered as symmetric.
Table I Distance And Demands For Customers

\begin{tabular}{|c|c|c|}
\hline Customer & Location & Demand \\
\hline 1 & $(40,40)$ & 12 \\
\hline 2 & $(36,26)$ & 21 \\
\hline 3 & $(21,45)$ & 25 \\
\hline 4 & $(45,35)$ & 15 \\
\hline 5 & $(10,10)$ & 16 \\
\hline 6 & $(55,45)$ & 24 \\
\hline 7 & $(26,59)$ & 12 \\
\hline 8 & $(55,15)$ & 17 \\
\hline 9 & $(40,30)$ & 20 \\
\hline 10 & $(20,14)$ & 25 \\
\hline
\end{tabular}

If $\mathrm{C}_{\mathrm{ab}} \neq \mathrm{C}_{\mathrm{ba}}$ means then the problem is asymmetric. Starting from the central warehouse, goods are delivered to the customers: $0-10$. Initially the distance for each customer is given. In Table 1, locations and the demands for each customer are given.

According to the existing scenario, Variable Neighborhood Search method uses the symmetric cost for returning to the depot, i.e. the distance from 1 to 5 is the same as the distance from 5 to 1 .

The location for the depot (or warehouse) is $(40,40)$ ( $\mathrm{x}$-axis and $\mathrm{y}$-axis values) and obviously the demand is zero. Based on the customer location, initially distance matrix is calculated using the Eq.(1) and its cost are symmetric. Eq.(1) represents the distance between the customer $\mathrm{c}_{\mathrm{i}}$ and the depot $\mathrm{k}$.

Eq.(1), Distance matrix formula

$$
D\left(c_{i}, k\right)=\sqrt{\left(x_{c_{i}}-x_{k}\right)^{2}+\left(y_{c_{i}}-y_{k}\right)^{2}}
$$


Table II Distance Matrix Calculation

\begin{tabular}{|c|c|c|c|c|c|c|c|c|c|c|}
\hline $\mathrm{C}_{\mathrm{ij}}$ & 0 & 1 & 2 & 3 & 4 & 5 & 6 & 7 & 8 & 9 \\
\hline 0 & - & $\begin{array}{l}1 \\
5\end{array}$ & $\begin{array}{l}2 \\
0\end{array}$ & 7 & $\begin{array}{l}4 \\
2\end{array}$ & $\begin{array}{l}1 \\
6\end{array}$ & $\begin{array}{l}2 \\
4\end{array}$ & $\begin{array}{l}2 \\
9\end{array}$ & $\begin{array}{l}1 \\
0\end{array}$ & $\begin{array}{l}3 \\
3\end{array}$ \\
\hline 1 & & - & $\begin{array}{l}2 \\
4\end{array}$ & $\begin{array}{l}1 \\
3 \\
\end{array}$ & $\begin{array}{l}3 \\
1 \\
\end{array}$ & $\begin{array}{l}2 \\
7 \\
\end{array}$ & $\begin{array}{l}1 \\
7 \\
\end{array}$ & $\begin{array}{l}2 \\
2 \\
\end{array}$ & 6 & $\begin{array}{l}2 \\
0 \\
\end{array}$ \\
\hline 2 & & & - & $\begin{array}{l}2 \\
6 \\
\end{array}$ & $\begin{array}{l}3 \\
7 \\
\end{array}$ & $\begin{array}{l}3 \\
4 \\
\end{array}$ & $\begin{array}{l}1 \\
5 \\
\end{array}$ & $\begin{array}{l}4 \\
5 \\
\end{array}$ & $\begin{array}{l}2 \\
4 \\
\end{array}$ & $\begin{array}{l}3 \\
1 \\
\end{array}$ \\
\hline 3 & & & & - & $\begin{array}{l}4 \\
3 \\
\end{array}$ & $\begin{array}{l}1 \\
4 \\
\end{array}$ & $\begin{array}{l}3 \\
1 \\
\end{array}$ & $\begin{array}{l}2 \\
2 \\
\end{array}$ & 7 & $\begin{array}{l}3 \\
3 \\
\end{array}$ \\
\hline 4 & & & & & - & $\begin{array}{l}1 \\
1\end{array}$ & $\begin{array}{l}5 \\
2\end{array}$ & $\begin{array}{l}4 \\
5\end{array}$ & $\begin{array}{l}3 \\
6\end{array}$ & $\begin{array}{l}1 \\
1\end{array}$ \\
\hline 5 & & & & & & - & $\begin{array}{l}3 \\
2\end{array}$ & $\begin{array}{l}3 \\
0\end{array}$ & $\begin{array}{l}2 \\
1\end{array}$ & $\begin{array}{l}4 \\
7\end{array}$ \\
\hline 6 & & & & & & & - & $\begin{array}{l}5 \\
3 \\
\end{array}$ & $\begin{array}{l}3 \\
2\end{array}$ & $\begin{array}{l}2 \\
5\end{array}$ \\
\hline 7 & & & & & & & & - & $\begin{array}{l}2 \\
1 \\
\end{array}$ & $\begin{array}{l}3 \\
5 \\
\end{array}$ \\
\hline 8 & & & & & & & & & - & $\begin{array}{l}2 \\
1\end{array}$ \\
\hline 9 & & & & & & & & & & - \\
\hline
\end{tabular}

Using the variable Neighborhood search method, the nearest neighbor for each customer is found. Based on that, the vehicles are routed for different destination points. Shaking step is applied at the last to minimize the overall total distance.

Table III Solution For VNS Algorithm With Three Routes

\begin{tabular}{|c|c|c|c|}
\hline & Trip & $\begin{array}{c}\text { Total } \\
\text { Distance }\end{array}$ & $\begin{array}{c}\text { Total } \\
\text { Demands }\end{array}$ \\
\hline Route1 & $0-3-8-4-0$ & 50 & 51 \\
\hline Route2 & $0-5-9-1-0$ & 83 & 70 \\
\hline Route3 & $0-2-6-7-0$ & 88 & 54 \\
\hline
\end{tabular}

Each vehicle is having same number of capacity limit. The maximum vehicle capacity defined for each vehicle in the above example is 70 . Table 3 shows that the result with the total distance of 221 and three vehicle is needed for that transportation. This method reduces the distance at a certain minimum compared to the earlier methods.

This decrease is not enough when the vehicle is used daily for delivering the goods to the customers, so for these kind of methods are proposed to solve all kinds of vehicle routing problems.

\section{Proposed Method}

The total distance is calculated while travelling to deliver the products to different destination points. The total distance is directly proportional to the total cost and total time. In vehicle routing problem, the main objective is need to find a route with minimum total distance. In the proposed work total distance travelled is considered as the first parameter.

Large instance set of problems which are mainly related to real world applications require more number of vehicles to cover several numbers of distribution points. In the proposed work planning to cover the several numbers of destination points with minimum number of vehicles. So the number of vehicles is considered as a second parameter.

In existing Variable Neighborhood Search method, initially the distance matrix values are calculated using the Eq.(1) and based on the calculated distance value Neighborhood for all the customers are found.

\section{A. Exaggerated Agglomerative Clustering Algorithm (EACA)}

The proposed approach is based on Agglomerative clustering algorithm for solving the vehicle routing problem with multiple repositories. By following the Exaggerated Agglomerative Clustering Algorithm, different clusters are found which is mainly used for routing the vehicles efficiently from the repository to all the destination points.

\section{A.1 Exaggerated Agglomerative Clustering Algorithm}

The algorithm steps as follows:

1 Choose the number of clusters, $\mathrm{k}$.

2 Randomly generate $\mathrm{k}$ clusters and determine the cluster centers, or directly generate $\mathrm{k}$ random points as cluster centers.

3 Assign each point to the nearest cluster center.

4 Recompute the new cluster centers. 
International Journal of Trend in Scientific Research and Development (IJTSRD) ISSN: 2456-6470

5 Repeat the two previous steps until some convergence criterion is met or the assignment has not changed.

6 Apply the search procedure for finding the final routes

\section{A.2 Flowchart for Exaggerated Agglomerative Clustering Algorithm}

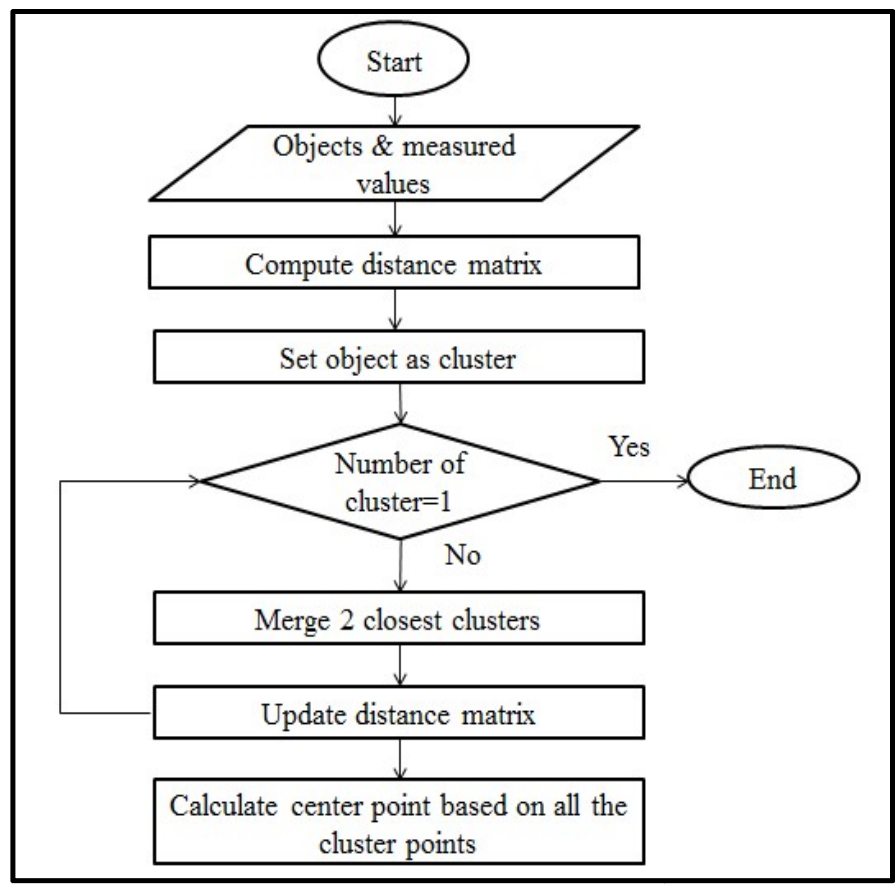

Fig.2 Exaggerated Agglomerative Clustering Algorithm

The flowchart for the Exaggerated Agglomerative Clustering Algorithm (EACA) is shown in the Figure 2. Using the Neighborhood search procedure, efficient routes are found for the vehicles which are going to deliver the goods to the customers. Simultaneously the total load for each vehicle doesn't exceed the maximum capacity of that vehicle.

\section{A.3 Statistical Example}

A set of 10 customers with their locations and demands are given in the Table 5. When the clustering is performed for a set of values, there may be two or more values can be formed. Based on the algorithm of Agglomerative clustering, two centroid values are found with two sets of different customers.
Table IV Customers With Location And Demands

\begin{tabular}{|c|c|c|c|}
\hline Customers & $\mathrm{A}$ (x-axis) & $\mathrm{B}$ (y-axis) & Demands \\
\hline $\mathbf{1}$ & 40 & 40 & 12 \\
\hline $\mathbf{2}$ & 36 & 26 & 21 \\
\hline $\mathbf{3}$ & 21 & 45 & 25 \\
\hline $\mathbf{4}$ & 45 & 35 & 15 \\
\hline $\mathbf{5}$ & 10 & 10 & 16 \\
\hline $\mathbf{6}$ & 55 & 45 & 24 \\
\hline $\mathbf{7}$ & 26 & 59 & 12 \\
\hline $\mathbf{8}$ & 55 & 15 & 17 \\
\hline $\mathbf{9}$ & 40 & 30 & 20 \\
\hline $\mathbf{1 0}$ & 20 & 14 & 25 \\
\hline
\end{tabular}

Table V Distance Matrix Calculation

\begin{tabular}{|c|c|c|c|c|c|c|c|c|c|c|}
\hline $\mathrm{C}_{\mathrm{ij}}$ & 0 & 1 & 2 & 3 & 4 & 5 & 6 & 7 & 8 & 9 \\
\hline 0 & - & $\begin{array}{l}1 \\
0\end{array}$ & $\begin{array}{l}1 \\
6\end{array}$ & $\begin{array}{l}1 \\
2\end{array}$ & $\begin{array}{l}3 \\
4\end{array}$ & $\begin{array}{l}2 \\
5\end{array}$ & $\begin{array}{l}2 \\
5\end{array}$ & $\begin{array}{l}3 \\
0\end{array}$ & 9 & $\begin{array}{l}2 \\
5\end{array}$ \\
\hline 1 & & - & $\begin{array}{l}2 \\
5 \\
\end{array}$ & $\begin{array}{l}1 \\
3 \\
\end{array}$ & $\begin{array}{l}3 \\
1 \\
\end{array}$ & $\begin{array}{l}2 \\
7 \\
\end{array}$ & $\begin{array}{l}3 \\
5 \\
\end{array}$ & $\begin{array}{l}2 \\
2 \\
\end{array}$ & 6 & $\begin{array}{l}2 \\
0\end{array}$ \\
\hline 2 & & & - & $\begin{array}{l}2 \\
6\end{array}$ & $\begin{array}{l}3 \\
7\end{array}$ & $\begin{array}{l}3 \\
4\end{array}$ & $\begin{array}{l}1 \\
5\end{array}$ & $\begin{array}{l}4 \\
6\end{array}$ & $\begin{array}{l}2 \\
5\end{array}$ & $\begin{array}{l}3 \\
2\end{array}$ \\
\hline 3 & & & & - & $\begin{array}{l}4 \\
4 \\
\end{array}$ & $\begin{array}{l}1 \\
5\end{array}$ & $\begin{array}{l}3 \\
1\end{array}$ & $\begin{array}{l}2 \\
3 \\
\end{array}$ & 8 & $\begin{array}{l}3 \\
3 \\
\end{array}$ \\
\hline 4 & & & & & - & $\begin{array}{l}5 \\
8\end{array}$ & $\begin{array}{l}5 \\
2\end{array}$ & $\begin{array}{l}4 \\
6 \\
\end{array}$ & $\begin{array}{l}3 \\
7\end{array}$ & $\begin{array}{l}1 \\
1\end{array}$ \\
\hline 5 & & & & & & - & $\begin{array}{l}3 \\
3\end{array}$ & $\begin{array}{l}3 \\
0\end{array}$ & $\begin{array}{l}2 \\
2\end{array}$ & $\begin{array}{l}4 \\
7\end{array}$ \\
\hline 6 & & & & & & & - & $\begin{array}{l}5 \\
3 \\
\end{array}$ & $\begin{array}{l}3 \\
3 \\
\end{array}$ & $\begin{array}{l}4 \\
6 \\
\end{array}$ \\
\hline 7 & & & & & & & & - & $\begin{array}{l}2 \\
2\end{array}$ & $\begin{array}{l}3 \\
6\end{array}$ \\
\hline 8 & & & & & & & & & - & $\begin{array}{l}2 \\
6\end{array}$ \\
\hline 9 & & & & & & & & & & - \\
\hline
\end{tabular}

Each customer belongs to one centroid point, otherwise called as depot. Using the Euclidean distance formula, the distance between the customers 
to particular depots is calculated and finally the total distance and the total number of vehicles needed to perform efficient transportation is found.

The final route points and their values which satisfy the termination condition is shown in the Table 6 . This method provides a better solution compared to the previous proposals by different authors.

Table VI EACA Result With Three Routes

\begin{tabular}{|c|c|c|c|}
\hline & Trip & $\begin{array}{c}\text { Total } \\
\text { Distance }\end{array}$ & $\begin{array}{c}\text { Total } \\
\text { Demands }\end{array}$ \\
\hline Route1 & $0-1-8-3-0$ & 24 & 56 \\
\hline Route2 & $0-4-9-5-0$ & 92 & 65 \\
\hline Route3 & $0-6-2-7-0$ & 86 & 49 \\
\hline
\end{tabular}

\section{Comparison Results}

The sample problems were solved by NetBeans IDE and the proposed Exaggerated Agglomerative Clustering Algorithm shows the best result while compared to Variable Neighborhood Search algorithm.

The result is analyzed based on the parameter called total distance. The comparison graph is shown in the Figure 3.

\section{Conclusion}

While calculating the savings matrix approach for the Variable Neighborhood method, it provides a good solution for the small instance set, but for a large instance set it doesn't yield a better result.

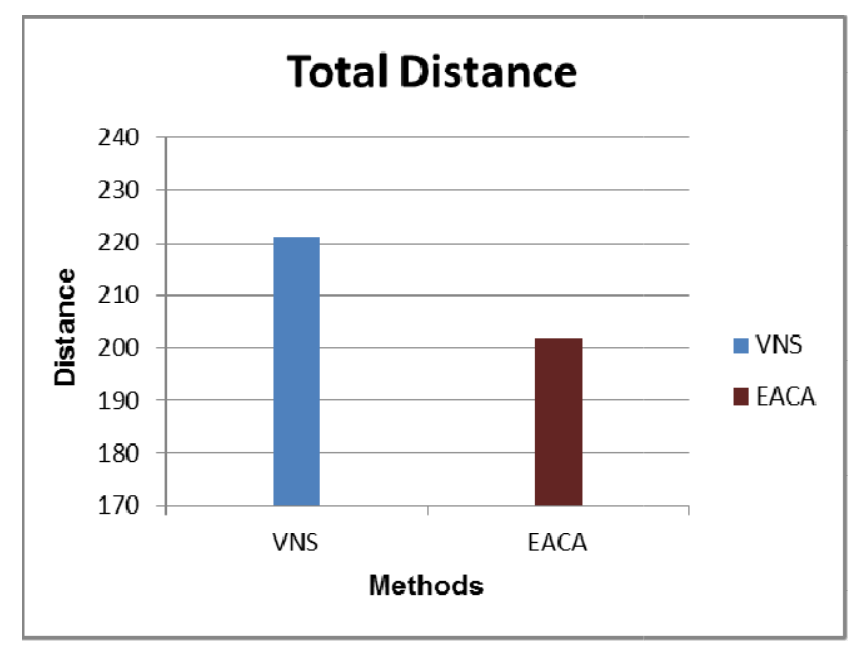

The proposed method shows a better solution against the previously proposed methods and exaggerated agglomerative clustering methods which are mainly used in the data mining concepts. Among all the existing methods, exaggerated agglomerative clustering method can reduce the total distance of about $7 \%$ while using multi depots for delivering the products to customers.

\section{References}

[1] Behrouz Afshar-Nadjafi, Alireza Afshar-Nadjafi, 2014. "A constructive heuristic for time dependent multidepot vehicle routing problem with timewindows and heterogeneous fleet", Journal of king saud university-Engineering sciences.

[2] Chopra, S., Meindl, P., 2004. Supply Chain Management -Strategy, Planning and Operation, $2^{\text {nd }}$ ed. Pearson Prentice hall, Upper Saddle River.

[3] G.B.Dantzig, J.H.Ramser, 1959. "The truck dispatching problem", Management Science, Vol. 6, No. 1, pp.80-91.

[4] G.Clarke, J.Wright, 1964. "Scheduling of vehicles from a central depot to a number of delivery points", Operations Research, Vol. 12, No. 4, pp. 568-581.

[5] Gaurav Sharma, Preeti Bansal, 2012. "Min-Min approach for scheduling in grid environment", International Journal of Latest Trends in Engineering and Technology(IJLTET), Vol 1, Issue 1.

[6] Graham K Rand, 2009. "The life and times of savings method for vehicle routing problems", http://www.orssa.org.za, Volume 25(2),pp.125-145.

[7] Gendreau M., A. Hertz and G. Laporte, A tabu search heuristic for the vehicle routing problem, Management Science 40 (1994), pp. 1276-1290.

[8] Olvera A. and O. Viera, Adaptive Memory Programming for the Vehicle Routing Problem with Multiple Trips, Computers \& Operations Research 34 (2007), pp. 28-47.

[9] Mohamed Cheikh, Mustapha Ratli, Omar Mkaouar, Baseem Jarboui, A Variable Neighborhood Search Algorithm for the vehicle routing problem with Multiple trips, Electronic notes in Discrete Mathematics 47(2015), Elsevier, pg 277-284

Fig.3 Total Distance 